\title{
Practical synthesis of enantiopure benzylamines by catalytic hydrogenation or transfer hydrogenation reactions in isopropanol using a Ru-pybox catalyst
}

Received 00th January 20xx, Accepted 00th January 20xx

DOI: $10.1039 / x 0 x \times 00000 x$

www.rsc.org/

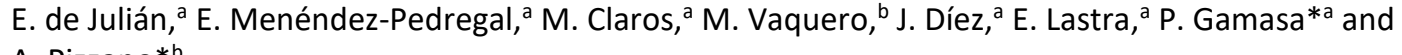
A. Pizzano*b

The screening of a family of complexes of formula $\left[R u C l_{2}(R-p y b o x)(L)\right]$ (R-pybox $=\mathrm{Ph}$-, ${ }^{\mathrm{P}} \mathrm{Pr}$ or indane-pybox; $\mathrm{L}=$ monodentate $\mathrm{P}, \mathrm{N}$ or $\mathrm{C}$ ligand) in the enantioselective hydrogenation of $\mathrm{N}$-aryl imines indicates a strong influence of the $\mathrm{R}$ pybox substituents and the $\mathrm{L}$ ligand in the process. A comparison indicates that best results are obtained with complex $\left[\mathrm{RuCl}_{2}(\mathrm{Ph}\right.$ pybox)(PPh(OMe $\left.\left.)_{2}\right)\right]$ which provided values of $99 \%$ ee for the reduction of several imines derived from aryl alkyl ketones. Worth to note, this complex is capable to reduce mentioned imines under transfer hydrogenation conditions using isopropanol as a hydrogen donor with equally high enantioselectivities.

\section{Introduction}

The development of efficient catalysts for the asymmetric hydrogenation of ketimines ${ }^{1}$ is a topic of high interest due to the paramount importance of chiral amines in the pharmaceutical, agrochemical and fragrances industries. ${ }^{2 a-2 c}$ Illustrative examples are pharmaceutical compounds A (Cinacalcet, Figure 1), ${ }^{2 \mathrm{~d}}$ B (NPS R-568) ${ }^{2 \mathrm{e}}$ and C (Rivastigmine), ${ }^{2 \mathrm{f}}$ while $\mathbf{D}$ ( $S$-Salsolidine) is a naturally occurring alkaloid. ${ }^{2 \mathrm{~g}}$ Moreover, $\mathbf{E}$ (S-Metholachlor) ${ }^{2 \mathrm{~h}}$ is used as an herbicide and $\mathbf{F}$ is a potent sweetener. ${ }^{2 i}$

A breakthrough in this area arose with the industrial synthesis of compound $\mathbf{E}$, which included the asymmetric hydrogenation of a ketimine by an extremely active Ir catalyst as a key step. ${ }^{2 h}$ Thereafter, remarkable progresses have been achieved in the hydrogenation of ketimines with Ir catalysts ${ }^{3}$ as well as with catalysts based on other metals (e.g. Ti, Fe, Ru, Rh, Pd). ${ }^{4}$ Notwithstanding this vast amount of research, the range of substrates that can be reduced with high levels of enantioselectivity is still narrow and the synthetic implementation of this type of hydrogenation looks far from its potential, keeping a high interest on the study of new catalytic systems. At this regard, some promising results have been

\footnotetext{
a. Laboratorio de Compuestos Organometálicos y Catálisis (Unidad Asociada al CSIC), Departamento de Química Orgánica e Inorgánica, Instituto de Química Organometálica "Enrique Moles", Universidad de Oviedo, 33006 Oviedo, Spain b. Instituto de Investigaciones Químicas (IIQ) and Centro de Innovación en Química Avanzada (ORFEO-CINQA), CSIC and Universidad de Sevilla, Américo Vespucio 49, 41092 Sevilla, Spain.

Electronic Supplementary Information (ESI) available: [Full characterization of new compounds. CCDC 1558476 (1d) and CCDC 1558477 (3j) contain the supplementary crystallographic data for this paper. See DOI: 10.1039/x0xx00000x
}

reported with $\mathrm{Ru}$ catalysts. For instance, the group of<smiles>C[C@H](NCCCc1cccc(C(F)(F)F)c1)c1cccc2ccccc12</smiles>

A (Cinacalcet)<smiles>CCN(C)C(=O)Oc1cccc([C@H](C)N(C)C)c1</smiles>

C (Rivastigmine)<smiles>CCc1cccc(C)c1N(C(=O)CCl)C(C)COC</smiles>

E (S-Metholachlor)

Figure 1 Examples of relevant chiral amines with common names in brackets.

Morris has reported a moderate enantioselectivity (ca. $70 \%$ ee) using complexes based on BINAP diphosphine and DPEN or $\mathrm{DACH}$ diamines in the hydrogenation of 1-methylbenzyliden aniline. ${ }^{5}$ Likewise, Cobley and coworkers have obtained up to 94 $\%$ ee in the hydrogenation of the latter substrate using a catalyst based on Et-Duphos and DACH ligands. ${ }^{6}$ In addition, Ohkuma and coworkers have reported that $\left[\mathrm{RuBr}_{2}(\mathrm{Xyl}-\right.$ skewphos)(DPEN)] leads to a highly enantioselective catalyst (91-99\% ee) for the hydrogenation of a wide variety of aryl imines derived from aryl-alkyl ketones. ${ }^{7}$ Moreover, we have shown that complexes based on phosphine-phosphite and DPEN ligands also provide high enantioselectivities (93-96 \% ee) 
in the latter type of hydrogenations. ${ }^{8}$ Worth to mention in this context, Fan and coworkers have described an alternative system based on a $\mathrm{Ru}$ arene diamine complex and $\mathrm{Boc}_{2} \mathrm{O}$ or a chiral phosphoric acid as additives. ${ }^{9}$

On the other hand, enantioselective hydrogen transfer reactions provide an operationally simpler and convenient alternative to hydrogenation for the synthesis of chiral amines, as they do not require pressurized hydrogen and the corresponding costly equipment. ${ }^{10}$ Moreover, the use of isopropanol for these reactions may even be a superior approach to the use of formic acid or its mixture with triethylamine, ${ }^{11}$ if the nature of the byproducts formed or the unnecessary control of $\mathrm{pH}$ in the former case are considered. However, the use of isopropanol for the asymmetric reduction of imines has only found a limited success to date. ${ }^{12-14}$ For instance, catalysts described by the groups of Morris and Beller efficiently reduced $N$-phosphinyl imines with high enantioselectivities, while these catalysts did not show activity in the case of unactivated $\mathrm{N}$-aryl imines. ${ }^{12,13}$ On the other hand, a chiral acid cocatalyst was required for the attainment of good activity and high enantioselectivity in the Ir catalyzed transfer hydrogenation of $\mathrm{N}$-aryl imines using alcohols. ${ }^{15}$ Moreover, Bäckvall has reported an efficient non-asymmetric reduction of imines using Shvo catalyst, ${ }^{16}$ while Hayashi and Dou have developed chiral versions of the latter, which displayed activity in the reduction of $\mathrm{N}$-aryl imines with isopropanol but with moderate enantioselectivities. ${ }^{17}$

In a preliminary communication we reported that complexes $\left[\mathrm{RuCl}_{2}(\mathrm{Ph}\right.$-pybox $\left.)(\mathrm{L})\right]\left(\mathrm{L}=\mathrm{P}(\mathrm{OMe})_{3}\right.$ and $\mathrm{P}(\mathrm{OEt})_{3}$, Figure 2$)$ are capable to reduce some $\mathrm{N}$-aryl imines with high enantioselectivity both under hydrogenation and transfer hydrogenation conditions in isopropanol, ${ }^{18}$ thus constituting the first example of an imine asymmetric hydrogenation/transfer hydrogenation network, reminiscent of those described for ketones in the literature. ${ }^{19}$ Despite the fundamental interest of this finding, the synthetic relevance of these reactions was limited, since catalysts only displayed enough activity to complete reactions with $\mathrm{S} / \mathrm{C}=100$ with a small number of imines, depicting a rather narrow substrate scope. Committed to find a more synthetically useful catalyst we aborded a broad study covering a wide range of $\left[\mathrm{RuCl}_{2}(\mathrm{R}-\right.$ pybox)(L)] complexes, differing in the nature of the monodentate ancillary ligand $L$ and the $R$ pybox substituents for the two kind of reductions. The results of this study, which we present in this full paper, have allowed us to find a superior catalyst both in terms of activity and substrate scope for the two types of processes, useful to prepare a sort of important chiral amines in enantiopure form.

\section{Results and discussion}

\section{Range of catalyst precursors and substrates examined}

For the present study, a wide set of Ru catalyst precursors bearing pybox and diverse monodentate $\mathrm{P}, \mathrm{N}$ and $\mathrm{C}$ ligands for the enantioselective hydrogenation and transfer

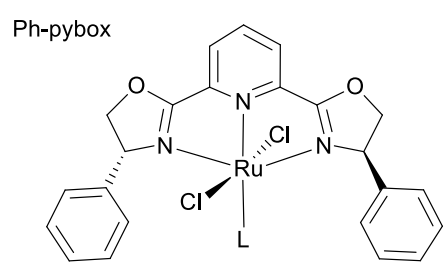

$\mathrm{L}=\mathrm{C}_{2} \mathrm{H}_{4}(\mathbf{1} \mathbf{a}), \mathrm{PPh}_{3}(\mathbf{1} \mathbf{b})$, $\mathrm{PPh}_{2} \mathrm{Me}(1 \mathrm{c}), \mathrm{P}(\mathrm{OMe})_{3}(\mathbf{1 d})$, $\mathrm{P}(\mathrm{OEt})_{3}(\mathbf{1 e}), \mathrm{P}\left(\mathrm{O}^{\mathrm{i} P r}\right)_{3}$ (1f), $\mathrm{P}\left(\mathrm{OCH}_{2}\right)_{3} \mathrm{CEt}(\mathbf{1 g}), \mathrm{PPh}_{2}(\mathrm{OMe})$ (1h), $\mathrm{PPh}_{2}$ (OEt) (1i), $\mathrm{PPh}(\mathrm{OMe})_{2}(\mathbf{1 j}), \mathrm{CNBn}(\mathbf{1 k})$, CNCy (1I), MeCN (1m)

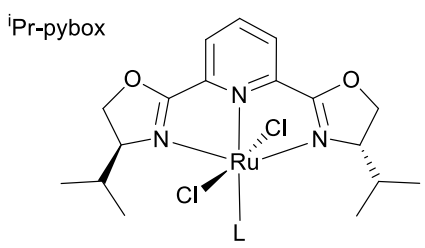

$\mathrm{L}=\mathrm{C}_{2} \mathrm{H}_{4}(\mathbf{2 a}), \mathrm{PPh}_{2}(\mathrm{OMe})(\mathbf{2 h})$, $\mathrm{PPh}_{2}(\mathrm{OEt})(\mathbf{2 i}), \mathrm{PPh}(\mathrm{OMe})_{2}(\mathbf{2 j})$

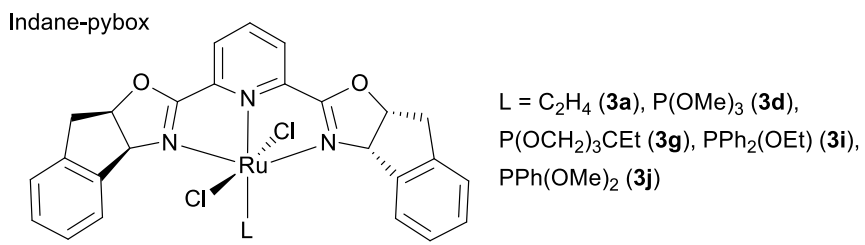

Figure $\mathbf{2}$ Structures of Ru complexes used in the present study

hydrogenation of imines has been examined (Figure 2). In addition to phosphine and phosphite derivatives of $\mathrm{Ph}$-pybox and indane-pybox ligands (1/b-1g, 3d and $\mathbf{3 g}$ ) used in our preliminary work, we have prepared phosphinite $(\mathbf{1} \mathbf{h}-\mathbf{1 i}, \mathbf{2} \mathbf{h}-\mathbf{2} \mathbf{i}$ and $\mathbf{3 i}$ ) and phosphonite derivatives $(\mathbf{1} \mathbf{j}, \mathbf{2} \mathbf{j}$ and $\mathbf{3} \mathbf{j})$, as well as isonitrile $(\mathbf{1 k}, \mathbf{1 l})$ and acetonitrile $(\mathbf{1 m})$ complexes for the present study, to examine in detail the influence of the $L$ ligand in these catalytic processes. New compounds have been prepared in good yield from the corresponding ethylene derivatives trans- $\left[\mathrm{RuCl}_{2}(\mathrm{R}\right.$-pybox $\left.)\left(\mathrm{C}_{2} \mathrm{H}_{4}\right)\right]\{\mathrm{R}$-pybox $=\mathrm{Ph}$-pybox (1a), iPr-pybox (2a) and indane-pybox (3a)\} and L ligands, although different reaction conditions were required depending on the combination of R-pybox and L ligands (see supporting for details).

Complexes 1-3 showed in ${ }^{1} \mathrm{H}$ and ${ }^{13} \mathrm{C}\left\{{ }^{1} \mathrm{H}\right\}$ NMR spectra only one set of signals for the two oxazoline fragments, indicative of a $C_{2}$ symmetric structure. Accordingly, these complexes should possess two chloro ligands in mutually trans positions, while the L ligand should occupy a coordination position trans to the pyridine fragment. This stereochemistry has been confirmed by single-crystal $\mathrm{X}$-ray analysis in the case of representative complexes $\mathbf{1 d}$ and $\mathbf{3 j}$ (Figures 3 and 4 ). While Ru- $\mathrm{N}$ distances and $\mathrm{N}$-Ru-N angles observed fall in the range observed for other related $\mathrm{Ru}(\mathrm{II})$ pybox complexes, ${ }^{20}$ an interesting aspect of these structures upon comparison regards the shape of the chiral cavity formed by the pybox ligand around the Ru atom. Thus, the two complexes differ in the inclination of the oxazoline aryl substituents with respect to the equatorial plane of the complex. For 1d $\mathrm{Ru}(1)-\mathrm{N}(1)-\mathrm{C}(7)-\mathrm{C}(6)$ and $\mathrm{Ru}(1)-\mathrm{N}(3)-\mathrm{C}(17)-$ $C(18)$ torsions amounted $-71(1)$ and $-74.9(11)$ deg. In contrast, for $\mathbf{3 j}$ values of $89.7(11)$ and $80.7(9)$ deg were obtained for $\mathrm{Ru}(1)-\mathrm{N}(1)-\mathrm{C}(9)-\mathrm{C}(1)$ and $\mathrm{Ru}(1)-\mathrm{N}(3)-\mathrm{C}(17)-\mathrm{C}(25)$, respectively. Accordingly, a higher steric interaction between 


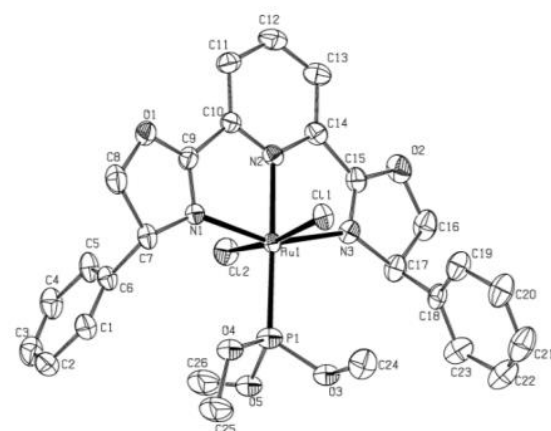

Figure 3. ORTEP view of the complex 1d (hydrogen atoms are omitted for clarity.

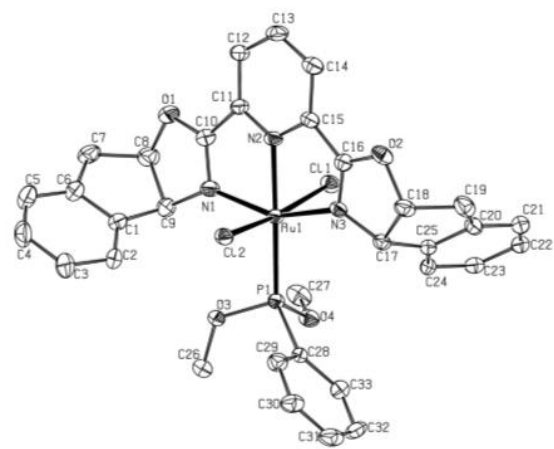

Figure 4. ORTEP drawing of the complex $\mathbf{3} \mathbf{j}$ (hydrogen atoms are omitted for clarity).

these aryl substituents and ligands occupying axial positions is expected for complexes bearing indane-pybox ligands, as shown by the distances between $\mathrm{Cl}$ and aryl $\mathrm{C}_{\text {ipso }}$ atoms (4.22(1) and 4.23(1) Å in 1d; 4.08(1) and 3.97(1) $\AA$ in 3j). As well, the lack of aryl rotation in the indane pybox ligand should enhance this steric effect.

Regarding the range of substrates, we have considered a wide variety of $\mathrm{N}$-aryl imines $4 a-4 p$ (Figure 5 ). In addition, to explore alternative $N$ protecting groups $N$-benzyl and $N$-allyl substrates $\mathbf{4 q}$ and $\mathbf{4 u}$, respectively, have been included in the set. As well, $\mathrm{N}$-propyl imine $\mathbf{4 r}$ was considered to investigate the influence of the $N$-aryl substituent in the reaction, while $4 \mathbf{s}$ was chosen as a representative example of challenging imines from dialkyl ketones. Finally $\mathbf{4 t}$, as well as $\mathbf{4 u}$, were examined to investigate the selectivity of these catalysts to reduce $\mathrm{C}=\mathrm{N}$ over $\mathrm{C}=\mathrm{C}$ bonds.

\section{Screening of complexes 1-3 in the hydrogenation of imine 4a}

Our preliminary study on the hydrogenation of representative 4a with Ph-pybox catalyst precursors $\mathbf{1 a}-\mathbf{1 g}\left(20 \mathrm{bar} \mathrm{H}_{2}\right.$, $\mathrm{PrOH}, 60$ ${ }^{\circ} \mathrm{C}, \mathrm{S} / \mathrm{C} / \mathrm{B}=100 / 1 / 5, \mathrm{KO}{ }^{\mathrm{t}} \mathrm{Bu}$ as base), ${ }^{18}$ indicated a critical influence of the $L$ ligand in the process (entries 1-7, Table 1. Thus, best results (95-99\% conv, 97-99\% ee; entries 4-5) were provided by catalysts bearing $\mathrm{P}(\mathrm{OMe})_{3}$ and $\mathrm{P}(\mathrm{OEt})_{3}$ ligands, superior to other phosphite derivatives (entries 6,7 ). In sharp contrast, phosphine derivatives showed very low conversion values (entries 2,3 ).

To fill the range of electronic properties of the phosphorus ancillary ligand we have included herein catalyst precursors bearing phosphinite $(\mathbf{1} \mathbf{h}, \mathbf{1} \mathbf{i})$ and phosphonite $(\mathbf{1} \mathbf{j})$ ligands, with intermediate basicity between that of phosphines and phosphites \{i.e. $\mathrm{PPh}_{3}>\mathrm{PPh}_{2}(\mathrm{OMe}), \mathrm{PPh}_{2}(\mathrm{OEt})>\mathrm{PPh}(\mathrm{OMe})_{2}>$ $\mathrm{P}(\mathrm{OMe})_{3}, \mathrm{P}(\mathrm{OEt})_{3}$. Satisfyingly, catalyst precursors $\mathbf{1 h}$ and $\mathbf{1 j}$ provided full conversion (entries 8, 10), while $\mathbf{1 i}$ afforded a slightly lower value (94\%, entry 9 ). Moreover, excellent values of enantioselectivity, between 95 and $99 \%$ ee, were obtained with the three complexes.

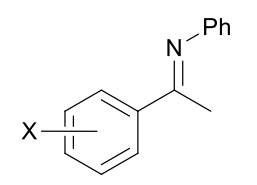

$X=\mathrm{H}(\mathbf{4 a}), 4-\mathrm{F}(\mathbf{4 b})$,

4-Cl (4c), 3-OMe (4d)<smiles>C/C(=N\C(C)C)c1ccc2ccccc2c1</smiles>

$4 n$<smiles>[X]c1ccc(C(C)=N[GaH2])cc1</smiles>

$X=H(4 e), 4-B r(4 f), 3-B r(4 g)$

2-Me (4h), 4-Me (4i), 2-F (4j), 4-CF 3 (4k),

3-OMe (4I), 3,4-(OMe) $)_{2}(4 \mathrm{~m})$<smiles>C/C(=N\C(C)C)c1cccc2ccccc12</smiles>

40<smiles>CC/C(=N\c1ccccc1)c1ccccc1</smiles>

$4 p$
$4 s$<smiles>C/C(=N/Cc1ccccc1)c1ccccc1</smiles>

$4 q$<smiles>CC(/C=C/c1ccccc1)=N/N=C/c1ccccc1</smiles>

$4 t$<smiles>CCC/N=C(\C)c1ccccc1</smiles>

$4 r$<smiles>C=CC/N=C(/C)c1ccccc1</smiles>

$4 u$

$$
\mathrm{An}=4-\mathrm{MeO}-\mathrm{C}_{6} \mathrm{H}_{4}
$$

Figure $\mathbf{5}$ Structure of imine substrates $\mathbf{4}$ covered in the present study.

Table 1. Hydrogenation of 4a with $\left[\mathrm{RuCl}_{2}(\mathrm{Ph}-\mathrm{pybox})(\mathrm{L})\right]$ complexes ${ }^{\mathrm{a}}$

\begin{tabular}{|c|c|c|}
\hline$N^{-P h}$ & $\mathrm{H}_{2}$ & $\mathrm{HN}^{-\mathrm{Ph}}$ \\
\hline $4 a$ & 1, base & $5 a$ \\
\hline
\end{tabular}

\begin{tabular}{ccccc}
\hline Entry & Cat. & $\mathrm{L}$ & Conv $^{\mathrm{b}}$ & $\% \mathrm{ee}^{\mathrm{c}}$ \\
\hline 1 & $\mathbf{1 a}$ & $\mathrm{C}_{2} \mathrm{H}_{4}$ & 4 & n. d. \\
2 & $\mathbf{1 b}$ & $\mathrm{PPh}_{3}$ & 22 & n. d. \\
3 & $\mathbf{1 c}$ & $\mathrm{PPh}_{2} \mathrm{Me}$ & 17 & n. d. \\
4 & $\mathbf{1 d}$ & $\mathrm{P}(\mathrm{OMe})_{3}$ & 95 & $99(S)$ \\
5 & $\mathbf{1 e}$ & $\mathrm{P}(\mathrm{OEt})_{3}$ & 99 & $97(S)$ \\
6 & $\mathbf{1 f}$ & $\mathrm{P}(\mathrm{O} \mathrm{Pr})_{3}$ & 11 & n. d. \\
7 & $\mathbf{1 g}$ & $\mathrm{P}_{3}\left(\mathrm{OCH}_{2}\right)_{3} \mathrm{CEt}$ & 87 & $92(S)$ \\
8 & $\mathbf{1 h}$ & $\mathrm{PPh}_{2}(\mathrm{OMe})$ & $>99$ & $97(S)$ \\
9 & $\mathbf{1 i}$ & $\mathrm{PPh}_{2}(\mathrm{OEt})$ & 94 & $95(S)$ \\
10 & $\mathbf{1 j}$ & ${\mathrm{PPh}(\mathrm{OMe})_{2}}_{10}$ & $>99$ & $99(S)$ \\
11 & $\mathbf{1 k}$ & $\mathrm{CNBn}$ & 27 & $62(R)$ \\
12 & $\mathbf{1 l}$ & $\mathrm{CNCy}$ & 32 & $46(R)$ \\
13 & $\mathbf{1 m}$ & $\mathrm{MeCN}$ & 7 & n. d. \\
\hline
\end{tabular}

a Conditions: 20 bar $\mathrm{H}_{2}, 60{ }^{\circ} \mathrm{C}$, $\mathrm{PrOH}, \mathrm{S} / \mathrm{C} / \mathrm{B}=100 / 1 / 5,[\mathrm{~S}]=0.15 \mathrm{M}$, using KO'Bu dissolved in $\mathrm{PrOH}$ as a base, reaction time $24 \mathrm{~h}$. ${ }^{\mathrm{b}}$ Conversion was determined by ${ }^{1} \mathrm{H}$ NMR. ' ${ }^{\mathrm{E}}$ nantiomeric excess analyzed by HPLC (n. d. = not determined), product configuration in brackets. 
Upon the positive influence of $\pi$-acidic $\mathrm{P}$ ligands, isonitrile derivatives $(\mathbf{1 k}, \mathbf{1})$ were also tested as potentially useful catalysts. However, contrary to our expectations, they displayed both low levels of conversion and enantioselectivity (entries 11, 12). In addition, complex $1 \mathrm{~m}$ bearing donor acetonitrile ligand, provided a very low conversion (entry 13). As well, a derivative of a $\mathrm{NHC}$ type ligand $\left[\mathrm{RuCl}_{2}\right.$ ( $\mathrm{Ph}$-pybox $)(1,3-$ dimethylimidazol-2-ylidene)] displayed an unsatisfactory performance ( $45 \%$ conv, $22 \%$ ee; not shown in Table 1). ${ }^{21}$

An alternative element for catalyst modulation corresponds to the pybox ligand and at this regard we have studied the Pr- and indane-pybox analogues of the best catalysts of series 1 . First, results obtained with 'Pr-pybox derivatives $\mathbf{2} \mathbf{d}$ and $\mathbf{2 h} \mathbf{\mathbf { 2 }} \mathbf{\mathbf { j }}$ (entries 1-4, Table 2) showed a catalyst performance far from shown by the corresponding Ph-pybox analogues, exhibiting only low to moderate conversions (24-51 \%) and poor enantioselectivities (up to $26 \%$ ee). For the series of indane-pybox complexes, complexes with $\mathrm{P}(\mathrm{OMe})_{3}$ and $\mathrm{PPh}(\mathrm{OMe})_{2}$ ligands (entries 5 and 8 , respectively) behave similarly to their Ph-pybox counterparts, while $\mathrm{P}\left(\mathrm{OCH}_{2}\right)_{3} \mathrm{CEt}(\mathbf{3 g}$, entry 6$)$ and $\mathrm{PPh}_{2}(\mathrm{OEt})$ complexes ( $\mathbf{3 i}$, entry 7) were less active and enantioselective than $\mathbf{1} \mathbf{g}$ and $\mathbf{1 i}$, respectively.

Overall, this screening shows two important features of the catalyst design. First, best results are obtained with $\pi$ acidic phosphorus L ligands. Second, the presence of aromatic substituents in the oxazoline fragments of the pybox ligands strongly favours both catalyst activity and high enantioselectivity.

After the positive results obtained with some of the catalysts at $\mathrm{S} / \mathrm{C}=100$, we next examined their utility at higher substrate to catalyst ratios (Table 3 ). Thus, when catalyst precursors $\mathbf{1 d}, \mathbf{1 e}$ and $\mathbf{1 h}$ were tested at $\mathrm{S} / \mathrm{C}=500$ under otherwise standard reaction conditions, uncompleted reactions were observed (entries $\mathbf{1}-\mathbf{3}$ ). In contrast, $\mathbf{1} \mathbf{j}$ and $\mathbf{3} \mathbf{j}$ provided full conversion and an excellent enantioselectivity (98-99\% ee, entries 4,7$)$ under these reaction conditions. For reactions performed at $\mathrm{S} / \mathrm{C}=$ $1000 \mathbf{1 j}$ still displayed a relatively good conversion ( $85 \%$, entry $5)$, while for $\mathbf{3} \mathbf{j}$ it decreased significantly (entry 8 ). Finally, $\mathbf{1} \mathbf{j}$ showed a moderate conversion at $\mathrm{S} / \mathrm{C}=2000$ (43\%, entry 6$)$ but without an erosion on enantioselectivity.

\section{Scope of catalysts 1 in the hydrogenation of imines 4}

Following the unsatisfactory substrate scope by $\mathbf{1 d}$ in the hydrogenation of diverse imines $\mathbf{4}$ (a more complete screening can be found in the supplementary material), we alternatively examined the scope of $\mathbf{1} \mathbf{j}$. Gratifyingly, this catalyst precursor provided a remarkable improvement in activity with most of substrates examined. Accordingly, $\mathbf{4 b}$ (entry 1 , Table 4), 4d-4e (entries 3,4 ), $\mathbf{4 i}$ (entry 8 ) and $\mathbf{4 k - 4} \mathbf{p}$ (entries 10-15) completed the reaction under our standard conditions. As well, the catalyst is effective for demanding ortho substituted imines. ${ }^{7}$ Thus $\mathbf{4 j}$ was efficiently reduced under the same reaction conditions (entry 9), whereas the corresponding hydrogenation of 2-Me substituted imine $\mathbf{4 h}$ is slower (60\% conversion, entry 6 ), but just an increase in reaction temperature $\left(70^{\circ} \mathrm{C}\right)$ and substrate concentration $([\mathrm{S}]=0.30 \mathrm{M}$ ) led the reaction to completion (entry 7). In sharp contrast, chloro- and bromo-substituted imines exhibited a poor performance. Thus, low conversion values were observed for $\mathbf{4 c}$ ( $44 \%, 79 \%$ ee; entry 2 ) and $\mathbf{4 f}$ ( 25 $\%$, entry 5 ), while no reaction was detected for $\mathbf{4 g}$. This is a general feature of this catalytic system and $\mathbf{1 i}$ showed similar results ( $40 \%$ conv and $61 \%$ ee for $\mathbf{4 c}$; $13 \%$ conv for $\mathbf{4 f}$; data not included in Table 4), likewise $\mathbf{1 d}$ did not show reaction with these substrates. This lack of reactivity has also been observed under transfer hydrogenation conditions (see below for further comments).

Moreover, $\mathbf{1} \mathbf{j}$ displayed an outstanding enantioselectivity for the reactive substrates and corresponding amines $\mathbf{5}$ were obtained with $99 \%$ ee. In addition, to explore the synthetic potential of the present catalytic system, an experiment to provide a higher productivity of the chiral amine using a more practical high substrate concentration was prepared. Satisfyingly, the hydrogenation of $4 \mathrm{l}$ using $6 \mathrm{mmol}$ of substrate $(1.53 \mathrm{~g})$ at a $\mathrm{S} / \mathrm{C}$ ratio of 500 ([S] = $2 \mathrm{M}$, IPA-toluene 1:1) under 20 bar $\mathrm{H}_{2}$ at $60^{\circ} \mathrm{C}$ quantitatively provided amine $5 \mathrm{I}$ in $24 \mathrm{~h}$ with a $98 \%$ ee.

Table 2. Hydrogenation of 4 a with ${ }^{\mathrm{P} r}$ - and indane-pybox catalysts ${ }^{\mathrm{a}}$

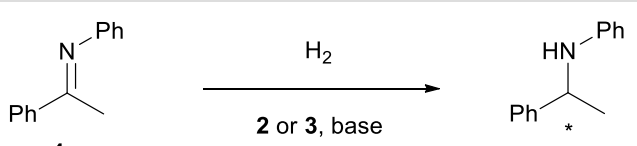

$4 a$

\begin{tabular}{cccccc}
\hline Entry & Cat. & $\mathrm{R}$ & $\mathrm{L}$ & Conv $^{\mathrm{b}}$ & \% ee \\
\hline 1 & $\mathbf{2 d}$ & $\mathrm{i} \mathrm{Pr}$ & $\mathrm{P}(\mathrm{OMe})_{3}$ & 24 & $6(R)$ \\
2 & $\mathbf{2 h}$ & $\mathrm{i} \mathrm{Pr}$ & $\mathrm{PPh}_{2}(\mathrm{OMe})$ & 38 & $3(S)$ \\
3 & $\mathbf{2 i}$ & $\mathrm{i} \mathrm{Pr}$ & $\mathrm{PPh}_{2}(\mathrm{OEt})$ & 51 & $4(S)$ \\
4 & $\mathbf{2 j}$ & $\mathrm{i} \mathrm{Pr}$ & $\mathrm{PPh}(\mathrm{OMe})_{2}$ & 33 & $26(R)$ \\
5 & $\mathbf{3 d}$ & indane & $\mathrm{P}(\mathrm{OMe})_{3}$ & 95 & $95(R)$ \\
6 & $\mathbf{3 g}$ & indane & $\mathrm{P}^{\mathrm{O}}\left(\mathrm{OCH}_{2}\right)_{3} \mathrm{CEt}$ & 79 & $63(R)$ \\
7 & $\mathbf{3 i}$ & indane & $\mathrm{PPh}_{2}(\mathrm{OEt})$ & 58 & $80(R)$ \\
8 & $\mathbf{3 j}$ & indane & $\mathrm{PPh}(\mathrm{OMe})_{2}$ & $>99$ & $99(R)$ \\
\hline
\end{tabular}

aConditions: 20 bar $\mathrm{H}_{2}, 60^{\circ} \mathrm{C}$, iPrOH, S/C/B = 100/1/5, [S] = $0.15 \mathrm{M}$, using KO'Bu dissolved in $\mathrm{PrOH}$ as a base, reaction time $24 \mathrm{~h}$. ${ }^{\mathrm{b}}$ Conversion was determined by ${ }^{1} \mathrm{H}$ NMR. 'Enantiomeric excess analyzed by HPLC, product configuration in brackets.

Table 3. Hydrogenation of 4 a at low catalyst loadings ${ }^{a}$

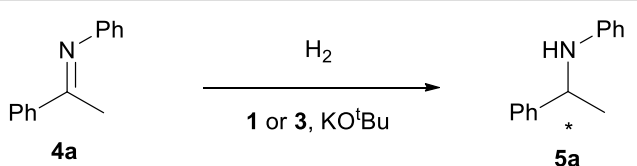

\begin{tabular}{ccccc}
\hline Entry & Cat. & S/C & Conv $^{\mathrm{b}}$ & \% ee $^{\mathrm{c}}$ \\
\hline 1 & $\mathbf{1 d}$ & 500 & 87 & $98(S)$ \\
2 & $\mathbf{1 e}$ & 500 & 65 & $97(S)$ \\
3 & $\mathbf{1 h}$ & 500 & 88 & $92(S)$ \\
$4^{\text {d }}$ & $\mathbf{1 j}$ & 500 & $>99$ & $99(S)$ \\
5 & $\mathbf{1 j}$ & 1000 & 85 & $97(S)$ \\
6 & $\mathbf{1 j}$ & 2000 & 43 & $99(S)$ \\
7 & $\mathbf{3 j}$ & 500 & $>99$ & $98(R)$ \\
8 & $\mathbf{3 j}$ & 1000 & 44 & $87(R)$ \\
\hline
\end{tabular}

aConditions: 20 bar $\mathrm{H}_{2}, 60{ }^{\circ} \mathrm{C}$, $\mathrm{PrOH}, \mathrm{C} / \mathrm{B}=1 / 5,[\mathrm{~S}]=0.75-3.0 \mathrm{M}$, using $\mathrm{KO}^{\mathrm{t}} \mathrm{Bu}$ dissolved in $\mathrm{PrOH}$ as a base, reaction time $24 \mathrm{~h}$. ${ }^{\mathrm{b}}$ Conversion was determined by ${ }^{1} \mathrm{H}$ NMR. 'Enantiomeric excess analyzed by HPLC, product configuration in brackets. ${ }^{d} 91 \%$ isolated yield. 
As a final recall, considering the easy deprotection of $N$-anisyl amines, ${ }^{22}$ the obtention of enantiopure $5 \mathrm{5I}, \mathbf{5 m}, \mathbf{5 0}$ and $\mathbf{5 p}$ has a considerable interest since the corresponding primary amines are suitable precursors for compounds $\mathbf{B}^{2 \mathrm{e}} \mathbf{D},{ }^{2 \mathrm{~g}} \mathbf{A}^{2 \mathrm{~d}}$ and $\mathbf{F}^{2 \mathrm{i}}$ (Figure 1), respectively.

Alternatively, the change of the $\mathrm{N}$-Ph or $\mathrm{N}$-An group by an $\mathrm{N}$ benzyl, $N$-propyl or $N$-allyl one produced an important decrease in substrate reactivity. Thus, only low conversion values were obtained in the hydrogenation of $\mathbf{4 q}$ and $\mathbf{4 r}$ with catalyst precursors $\mathbf{1 d}$ and $\mathbf{1} \mathbf{j}$ (entries 1-4, Table 5). On the other hand, the hydrogenation of $4 \mathrm{u}$ mainly showed the reduction of the olefin bond (Scheme 1$)^{23}$ and $\mathbf{4 r} / \mathbf{5 r}$ ratios of $68 / 32$ and $70 / 30$ were obtained with $\mathbf{1} \mathbf{d}$ and $\mathbf{1 j}$, respectively. ${ }^{24}$ With regard to this reaction it should also be noticed that the allyl substrate fully isomerizes to the corresponding enamine $4 u^{\prime}(Z / E=45: 55$ ratio, Scheme 2) under basic conditions. ${ }^{25}$ Therefore, aside from a direct reduction of the allyl fragment, catalysts generated by $\mathbf{1 d}$ and $\mathbf{1} \mathbf{j}$ should reduce any $\mathbf{4} \mathbf{u}^{\prime}$ generated in the reaction to give $4 r$, which remains as the main product due to its low reactivity. As well, $\mathbf{1} \mathbf{j}$ and $\mathbf{1 d}$ completely hydrogenate the olefin bond of $\alpha, \beta$-unsaturated imine $4 t$, to give a mixture of the phenethyl imine $\left(\mathbf{4} \mathbf{t}^{\prime}\right)$ and amine (5t) in $\mathbf{4} \mathbf{t}^{\prime} / \mathbf{5 t}$ ratios of $49: 51$ and $70: 30$, respectively (Scheme 3 ), while the allyl amine resulting from the $\mathrm{C}=\mathrm{N}$ reduction of $\mathbf{4} \mathbf{t}$ was not observed.

Table 4. Hydrogenation of imines $4 \mathrm{~b}-\mathbf{4 p}$ with catalyst precursor $1 \mathrm{j}^{\mathrm{a}}$

\begin{tabular}{|c|c|c|c|c|}
\hline & & $\mathrm{H}_{2}$ & & \\
\hline Entry & Cat. & Imine $\left(A r, A r^{\prime}, R\right)$ & Conv $^{b}$ & $\% \mathrm{ee}^{\mathrm{c}}$ \\
\hline 1 & $1 \mathrm{j}$ & 4b (4-F-Ph, Ph, Me) & $>99(84)$ & $99(S)$ \\
\hline 2 & $1 \mathrm{j}$ & 4c (4-Cl-Ph, Ph, Me) & 44 & $79(S)$ \\
\hline 3 & $\mathbf{1 j}$ & 4d (3-MeO-Ph, Ph, Me) & $>99(88)$ & $99(S)$ \\
\hline 4 & $1 j$ & $4 \mathrm{e}(\mathrm{Ph}, \mathrm{An}, \mathrm{Me})$ & $>99(91)$ & $99(S)$ \\
\hline 5 & $\mathbf{1 j}$ & 4f (4-Br-Ph, An, Me) & 25 & n. d. \\
\hline 6 & $1 \mathbf{j}$ & 4h (2-Me-Ph, An, Me) & 60 & $97(S)$ \\
\hline $7^{d}$ & $1 \mathbf{j}$ & 4h (2-Me-Ph, An, Me) & $99(91)$ & $99(S)$ \\
\hline 8 & $1 \mathbf{j}$ & $4 \mathbf{i}(4-M e-P h, A n, M e)$ & $>99(75)$ & $99(S)$ \\
\hline 9 & $1 \mathbf{j}$ & $4 \mathbf{j}(2-\mathrm{F}-\mathrm{Ph}, \mathrm{An}, \mathrm{Me})$ & $98(92)$ & $99(S)$ \\
\hline 10 & $1 \mathrm{j}$ & $\mathbf{4 k}\left(4-\mathrm{CF}_{3}-\mathrm{Ph}, \mathrm{An}, \mathrm{Me}\right)$ & $>99(93)$ & $99(S)$ \\
\hline 11 & $1 \mathrm{j}$ & $4 \mathrm{l}$ (3-MeO-Ph, An, Me) & $>99(93)$ & $99(S)$ \\
\hline 12 & $1 \mathbf{j}$ & $4 \mathrm{~m}\left(3,4-(\mathrm{MeO})_{2}-\mathrm{Ph}, \mathrm{An}, \mathrm{Me}\right)$ & $>99(63)$ & $99(S)$ \\
\hline 13 & $1 \mathbf{j}$ & 4n (2-naphthyl, An, Me) & $>99(80)$ & $99(S)$ \\
\hline 14 & $1 j$ & 4o (1-naphthyl, An, Me) & $>99(73)$ & $99(S)$ \\
\hline 15 & $1 j$ & $4 p(P h, A n, E t)$ & $>99(80)$ & $99(S)$ \\
\hline
\end{tabular}

aConditions: 20 bar $\mathrm{H}_{2}, 60{ }^{\circ} \mathrm{C}, \mathrm{iPrOH}^{\mathrm{P}} \mathrm{S} / \mathrm{C} / \mathrm{B}=100 / 1 / 5$, [S] $=0.15 \mathrm{M}$, using KOtBu dissolved in $\mathrm{PrOH}$ as a base, reaction time $24 \mathrm{~h}$, unless otherwise stated. ${ }^{b}$ Conversion was determined by ${ }^{1} \mathrm{H}$ NMR, isolated yields in brackets. ${ }^{\mathrm{C}}$ Enantiomeric excess analyzed by HPLC ( $\mathrm{n}$. d. = not determined), configuration in brackets. ${ }^{\mathrm{d}}[\mathrm{S}]=$ $0.30 \mathrm{M}, 70^{\circ} \mathrm{C}$.<smiles>C=CC/N=C(\C)c1ccccc1</smiles>

4u

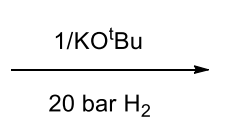

20 bar $\mathrm{H}_{2}$

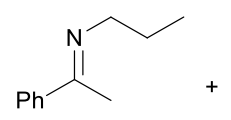

$4 r$

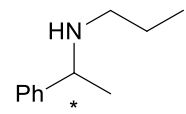

$5 r$

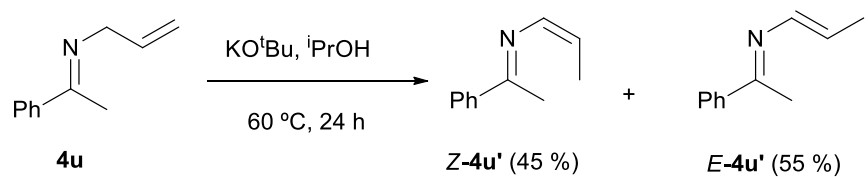

Scheme 2. Isomerization of $4 u$ under basic conditions.

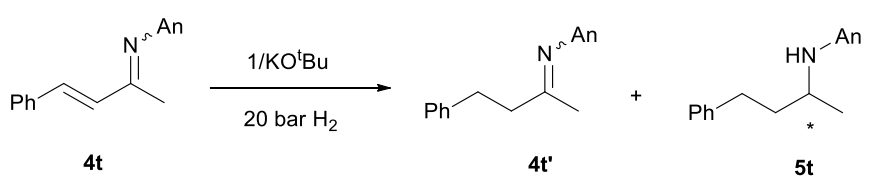

Scheme 3. Products observed in the reduction of $\alpha, \beta$-unsaturated imine $4 \mathbf{4 t}$.

Table 5. Hydrogenation of $\mathbf{4 q}$ and $\mathbf{4 r}$ with $\left[\mathrm{RuCl}_{2}(\mathrm{Ph}-\right.$ pybox $\left.)(\mathrm{L})\right]$ complexes $^{\mathrm{a}}$

\begin{tabular}{cccc} 
1, base & \multicolumn{2}{c}{} \\
\hline Entry & Cat. & Imine & Conv $^{\text {b }}$ \\
\hline 1 & $\mathbf{1 d}$ & $\mathbf{4 q}$ & 45 \\
2 & $\mathbf{1 j}$ & $\mathbf{4 q}$ & 30 \\
3 & $\mathbf{1 d}$ & $\mathbf{4 r}$ & 44 \\
4 & $\mathbf{1 j}$ & $\mathbf{4 r}$ & 32 \\
\hline
\end{tabular}

aConditions: 20 bar $\mathrm{H}_{2}, 60{ }^{\circ} \mathrm{C}$, $\mathrm{PrOH}, \mathrm{S} / \mathrm{C} / \mathrm{B}=100 / 1 / 5$, [S] $=0.15 \mathrm{M}$, using $\mathrm{KO}{ }^{\mathrm{t} B u}$ dissolved in $\mathrm{PrOH}$ as a base, reaction time $24 \mathrm{~h}$. ${ }^{\mathrm{b}}$ Conversion was determined by ${ }^{1} \mathrm{H}$ NMR.

Table 6. Hydrogenation of imine $4 s$ with $\left[\mathrm{RuCl}_{2}(\mathrm{R}-\mathrm{pybox})(\mathrm{L})\right]^{\mathrm{a}}$

\begin{tabular}{cccccc}
\hline & & & & \\
\hline
\end{tabular}

aConditions: 20 bar $\mathrm{H}_{2}, 60^{\circ} \mathrm{C}$ unless otherwise stated, $\mathrm{i} P \mathrm{Pr}, \mathrm{S} / \mathrm{C} / \mathrm{B}=100 / 1 / 5$, [S] = $0.15 \mathrm{M}$, using $\mathrm{KO}^{\mathrm{t}} \mathrm{Bu}$ dissolved in $\mathrm{PrOH}$ as a base, reaction time $24 \mathrm{~h}$. ${ }^{\mathrm{b}} \mathrm{Conversion}$ was determined by ${ }^{1} \mathrm{H}$ NMR. ${ }^{C}$ Enantiomeric excess analyzed by HPLC. ${ }^{\mathrm{d}}$ Reaction performed at $70^{\circ} \mathrm{C}$

A rather challenging type of prochiral imines for asymmetric hydrogenation is that constituted by those proceeding from dialkyl ketones. ${ }^{3 f-3 g}$ We have selected $4 \mathbf{s}$ as a representative example of this type of substrates and we have examined its hydrogenation with diverse catalyst precursors under our standard conditions. Disappointingly, only low to moderate conversion values were observed (17-33 \%, entries 1-7, Table $6)$. Best values of conversion and enantioselectivity were observed with catalyst from $\mathbf{1 j}$ (33\% conv, $51 \%$ ee; entry 3 ), while an increase in the reaction temperature increased the 
conversion up to $61 \%$ but unfortunately led to a racemic compound (entry 8$)$.

\section{Transfer hydrogenation of imines 4 using $\mathrm{P}$ POH}

To comparatively analyze the performance of complexes 1-3 in the reduction of $4 \mathrm{a}$ under transfer hydrogenation conditions (1 bar $\mathrm{N}_{2}$, $\mathrm{PrOH}, \mathrm{S} / \mathrm{C} / \mathrm{B}=100 / 1 / 5,60^{\circ} \mathrm{C}, 24 \mathrm{~h}$ ), we have completed our preliminary screening ${ }^{18}$ with data corresponding to the novel complexes (Table 7). Among these results, phosphite complexes 1d, 1e and 3d (entries 2, 4 and 16, respectively) and phosphonite complex $\mathbf{1} \mathbf{j}$ (entry 8 ) completed reactions with 99 $\%$ ee, while phosphinite complexes $\mathbf{1} \mathbf{h}, \mathbf{1} \mathbf{i}$ and $\mathbf{3 i}$ only provided low to moderate conversions (entries 6,7 and 18, respectively). Worth to note, iPr-pybox catalysts showed better enantioselectivities under transfer hydrogenation conditions than under hydrogenation ones, while for $\mathbf{2} \mathbf{j}$ a significant enhancement on conversion was also observed (entry 15).

Regarding reactions prepared at lower catalyst loadings $(\mathrm{S} / \mathrm{C}=$ 500 ) it should be added that $\mathbf{1 d}$ and $\mathbf{1} \mathbf{j}$ showed lower conversion values (entries 3 and 9, respectively) than in the corresponding hydrogenation reactions.

A preliminary analysis of the substrate scope of the transfer hydrogenation reaction with $\mathbf{1 d}$ showed a good performance with some imines 4 . Thus it provided full conversion and $99 \%$ ee for substrates $\mathbf{4 d - 4 e}$ (entries 3-4, Table $\mathbf{8}$ ), $\mathbf{4 i - 4 m}$ (entries 6-

Table 7. Transfer hydrogenation of $4 a$ with $\left[\mathrm{RuCl}_{2}\left(\mathrm{R}\right.\right.$-pybox)(L)] complexes ${ }^{\mathrm{a}}$

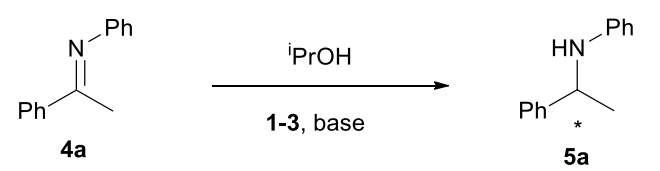

\begin{tabular}{|c|c|c|c|c|c|}
\hline Entry & Cat. & $\mathrm{R}$ & $\mathrm{L}$ & Conv $^{b}$ & $\% \mathrm{ee}^{\mathrm{c}}$ \\
\hline 1 & $1 b$ & $\mathrm{Ph}$ & $\mathrm{PPh}_{3}$ & $<5$ & n. d. \\
\hline 2 & $1 d$ & $\mathrm{Ph}$ & $\mathrm{P}(\mathrm{OMe})_{3}$ & $>99$ & $99(S)$ \\
\hline $3^{d}$ & $1 d$ & $\mathrm{Ph}$ & $\mathrm{P}(\mathrm{OMe})_{3}$ & 48 & $99(S)$ \\
\hline 4 & $1 e$ & $\mathrm{Ph}$ & $\mathrm{P}(\mathrm{OEt})_{3}$ & $>99$ & $99(S)$ \\
\hline 5 & $1 \mathrm{~g}$ & $\mathrm{Ph}$ & $\mathrm{P}\left(\mathrm{OCH}_{2}\right)_{3} \mathrm{CEt}$ & 84 & $95(S)$ \\
\hline 6 & 1h & $\mathrm{Ph}$ & $\mathrm{PPh}_{2}(\mathrm{OMe})$ & 59 & $91(S)$ \\
\hline 7 & $1 \mathbf{i}$ & $\mathrm{Ph}$ & $\mathrm{PPh}_{2}(\mathrm{OEt})$ & 19 & $71(S)$ \\
\hline 8 & $1 \mathrm{j}$ & $\mathrm{Ph}$ & $\mathrm{PPh}(\mathrm{OMe})_{2}$ & $>99$ & $99(S)$ \\
\hline $9^{d}$ & $1 \mathrm{j}$ & $\mathrm{Ph}$ & $\mathrm{PPh}(\mathrm{OMe})_{2}$ & 58 & $99(S)$ \\
\hline 10 & $1 k$ & $\mathrm{Ph}$ & CNBn & 4 & n. d. \\
\hline 11 & 11 & $\mathrm{Ph}$ & CNCy & 6 & n. d. \\
\hline 12 & $1 \mathrm{~m}$ & $\mathrm{Ph}$ & $\mathrm{MeCN}$ & $<5$ & n. d. \\
\hline 13 & $2 \mathrm{~h}$ & iPr & $\mathrm{PPh}_{2}(\mathrm{OMe})$ & 42 & $30(R)$ \\
\hline 14 & $2 \mathbf{i}$ & iPr & $\mathrm{PPh}_{2}(\mathrm{OEt})$ & 41 & $15(R)$ \\
\hline 15 & $2 j$ & iPr & $\mathrm{PPh}(\mathrm{OMe})_{2}$ & 98 & $71(R)$ \\
\hline 16 & $3 d$ & indane & $\mathrm{P}(\mathrm{OMe})_{3}$ & $>99$ & $99(R)$ \\
\hline 17 & $3 g$ & indane & $\mathrm{P}\left(\mathrm{OCH}_{2}\right)_{3} \mathrm{CEt}$ & 63 & $76(R)$ \\
\hline 18 & $3 \mathbf{i}$ & indane & $\mathrm{PPh}_{2}(\mathrm{OEt})$ & 4 & n. d. \\
\hline 19 & $3 \mathbf{j}$ & indane & $\mathrm{PPh}(\mathrm{OMe})_{2}$ & 85 & $97(R)$ \\
\hline
\end{tabular}

aConditions: 1 bar $\mathrm{N}_{2}, 60^{\circ} \mathrm{C}$, $\mathrm{PrOH}, \mathrm{S} / \mathrm{C} / \mathrm{B}=100 / 1 / 5,[\mathrm{~S}]=0.15 \mathrm{M}$, using $\mathrm{KO}{ }^{\mathrm{t}} \mathrm{Bu}$ dissolved in $\mathrm{PrOH}$ as a base, reaction time $24 \mathrm{~h}$, unless otherwise stated.

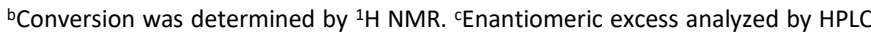
(n. d. = not determined), product configuration in brackets. ${ }^{d} S / C / B=500 / 1 / 5,[S]=$ $0.75 \mathrm{M}$
9), while for $\mathbf{4 b}$ near identical results than in the corresponding hydrogenation were obtained (93\% conv, $98 \%$ ee; entry 1 ). However, the reduction of substrates $\mathbf{4 n - 4 p}$ with $\mathbf{1 d}$ showed rather low conversion values (entries 10-12).

Moreover, $\mathbf{1} \mathbf{j}$ exhibited an outstanding performance giving high conversion and enantioselectivities ranging from 97 to $99 \%$ ee for imines $\mathbf{4 b}, \mathbf{4} \mathbf{d}-\mathbf{4 e}$ and $\mathbf{4 i - 4 0}$ (entries $13,15-16$ and 18-23), while $4 p$ showed a significantly lower conversion that under hydrogenation conditions (entry 24).

In contrast, halogenated substrates $\mathbf{4 c}$ and $\mathbf{4 f}$ constitute a limitation of the catalytic system. It has been mentioned before the low to negligible conversions observed under hydrogenation conditions with several catalysts. Parallel observations have been made under transfer hydrogenation ones (entries 2, 5, 14 and 17). We do not have a definite explanation for it, but this phenomenon seems associated to the particular hydrogenation of imines $\mathbf{4 c}$ and $\mathbf{4 f}$ (and presumibly for other bromo- and chloroaryl imines) with these catalysts since some catalysts 1 are capable to reduce 2-, 3- and 4-bromo acetophenone under hydrogen transfer conditions similar to those used here with high TOF. ${ }^{26}$ Moreover, in view of the good conversion obtained with

Table 8. Transfer hydrogenation of imines $\mathbf{4}$ with $\mathbf{1 d}$ and $\mathbf{1} \mathbf{j}$ catalyst precursors

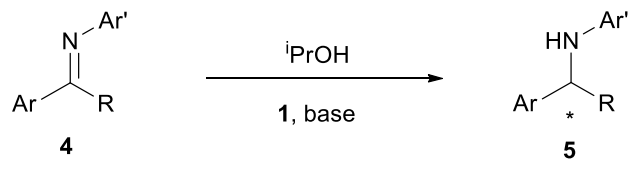

\begin{tabular}{|c|c|c|c|c|}
\hline Entry & Cat. & Imine $\left(\mathrm{Ar}, \mathrm{Ar}{ }^{\prime}, \mathrm{R}\right)$ & Conv $^{b}$ & $\% e^{c}$ \\
\hline 1 & 1d & 4b (4-F-Ph, Ph, Me) & 93 & $98(S)$ \\
\hline 2 & 1d & 4c (4-Cl-Ph, Ph, Me) & $<5$ & n. d. \\
\hline 3 & 1d & 4d (3-MeO-Ph, Ph, Me) & $>99$ & $99(S)$ \\
\hline 4 & 1d & $4 e(P h, A n, M e)$ & $>99$ & $99(S)$ \\
\hline 5 & 1d & $4 f(4-B r-P h, A n, M e)$ & $<5$ & n.d. \\
\hline 6 & 1d & 4i (4-Me-Ph, An, Me) & $>99$ & $99(S)$ \\
\hline 7 & 1d & $\mathbf{4 k}\left(4-\mathrm{CF}_{3}-\mathrm{Ph}, \mathrm{An}, \mathrm{Me}\right)$ & $>99$ & $99(S)$ \\
\hline 8 & 1d & $4 \mathrm{l}$ (3-MeO-Ph, An, Me) & $>99$ & $99(S)$ \\
\hline 9 & 1d & $4 \mathrm{~m}\left(3,4-(\mathrm{MeO})_{2}-\mathrm{Ph}, \mathrm{An}, \mathrm{Me}\right)$ & $>99$ & $99(S)$ \\
\hline 10 & 1d & 4n (2-naphthyl, An, Me) & 15 & n. d. \\
\hline 11 & 1d & 40 (1-naphthyl, An, Me) & 4 & n. d. \\
\hline 12 & 1d & $4 p(P h, A n, E t)$ & 12 & n. d. \\
\hline 13 & $1 \mathbf{j}$ & 4b (4-F-Ph, Ph, Me) & $>99(87)$ & $99(S)$ \\
\hline 14 & $1 \mathbf{j}$ & 4c (4-Cl-Ph, Ph, Me) & $<5$ & n. d. \\
\hline 15 & $1 \mathbf{j}$ & 4d (3-MeO-Ph, Ph, Me) & $>99(93)$ & $99(S)$ \\
\hline 16 & $1 \mathbf{j}$ & $4 \mathrm{e}(\mathrm{Ph}, \mathrm{An}, \mathrm{Me})$ & $>99(91)$ & $99(S)$ \\
\hline 17 & $1 \mathbf{j}$ & $4 f(4-B r-P h, A n, M e)$ & $<5$ & n. d. \\
\hline 18 & $1 \mathbf{j}$ & $4 \mathbf{i}(4-\mathrm{Me}-\mathrm{Ph}, \mathrm{An}, \mathrm{Me})$ & $>99(91)$ & $99(S)$ \\
\hline 19 & $1 \mathbf{j}$ & $\mathbf{4 k}\left(4-\mathrm{CF}_{3}-\mathrm{Ph}, \mathrm{An}, \mathrm{Me}\right)$ & $>99$ (99) & $99(S)$ \\
\hline 20 & $1 \mathbf{j}$ & $4 \mathrm{l}$ (3-MeO-Ph, An, Me) & $>99(98)$ & $99(S)$ \\
\hline 21 & $1 \mathrm{j}$ & $4 \mathrm{~m}\left(3,4-(\mathrm{MeO})_{2}-\mathrm{Ph}, \mathrm{An}, \mathrm{Me}\right)$ & $>99(65)$ & $99(S)$ \\
\hline 22 & $1 \mathbf{j}$ & 4n (2-naphthyl, An, Me) & $>99(98)$ & $99(S)$ \\
\hline 23 & $1 \mathbf{j}$ & 4o (1-naphthyl, An, Me) & 92 & $97(S)$ \\
\hline 24 & $1 \mathrm{j}$ & $4 p(P h, A n, E t)$ & 34 & $86(S)$ \\
\hline
\end{tabular}

aConditions: 1 bar $\mathrm{N}_{2}, 60^{\circ} \mathrm{C}$, $\mathrm{PrOH}, \mathrm{S} / \mathrm{C} / \mathrm{B}=100 / 1 / 5,[\mathrm{~S}]=0.15 \mathrm{M}$, using $\mathrm{KO}{ }^{\mathrm{t}} \mathrm{Bu}$ dissolved in $\mathrm{PrOH}$ as a base, reaction time $24 \mathrm{~h}$. ${ }^{\mathrm{b}}$ Conversion was determined by ${ }^{1} \mathrm{H}$ NMR, isolated yields for selected reactions in brackets. "Enantiomeric excess analyzed by HPLC ( $\mathrm{n}$. d. = not determined), configuration in brackets. 
substrates $\mathbf{4} \mathbf{b}$ and $\mathbf{4 k}$ (entries $\mathbf{1}, 7,13$ and 19), the lack of reactivity shown by $\mathbf{4 c}$ and $\mathbf{4 f}$ may not be attributed to the electron-withdrawing properties of the halogen aryl substituent.

On the other hand, in the reduction of $\mathrm{N}$-allyl imine $\mathbf{4} \mathbf{u}$ under transfer hydrogenation conditions using $\mathbf{1 d}$, the mixture of products mainly corresponded to enamine $\mathbf{4} \mathbf{u}^{\prime}\left(\mathbf{4} \mathbf{u}: Z-\mathbf{4} \mathbf{u}^{\prime}: E-\right.$

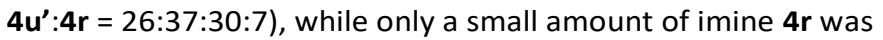
detected. Similar results were observed in the reaction using $\mathbf{1} \mathbf{j}$ $\left(4 \mathbf{u}: Z-4 \mathbf{u}^{\prime}: E-4 \mathbf{u}^{\prime}: \mathbf{4 r}=17: 44: 32: 7\right)$. Worth to note, the enamine $Z: E$ ratios (55:45 and 58:42 for $\mathbf{1} \mathbf{d}$ and $\mathbf{1} \mathbf{j}$, respectively) are rather similar to that obtained in the reaction in absence of metal complex, in good accord with a formation of the enamine by the base catalyzed reaction. Thus, these results indicate a low reactivity of the enamine under hydrogen transfer conditions.

\section{Mechanistic considerations}

The surprisingly similar performance under both hydrogenation and transfer hydrogenation conditions shown by precatalysts $\mathbf{1 d}$ and $\mathbf{1 e}$ in the reduction of $\mathbf{4 a}$, committed us to demonstrate in our preliminary communication the distinct nature of the hydrogen donor in the two types of reactions (i.e. hydrogen and iPrOH, respectively). At that regard, particularly clear was the different labelling observed in reactions performed in $\left(\mathrm{CH}_{3}\right)_{2} \mathrm{CHOD}$ (Scheme 4). ${ }^{18}$ To complete these observations, it looks of interest to investigate if isopropanol is needed for the reduction under hydrogenation conditions. It should be noticed in this context that base used in the present hydrogenation/transfer hydrogenation reactions is $\mathrm{KO}^{\mathrm{t}} \mathrm{Bu}$ dissolved in ${ }^{\mathrm{P}} \mathrm{POH}$, which actually corresponds to KO'Pr. ${ }^{19 a} \mathrm{~A}$ convenient alternative to the latter is commercially available $\mathrm{NaO}$ Pr. To check the suitability of this base, a control experiment with $\mathrm{NaO}$ 'Pr in ${ }^{\mathrm{PrOH}}$ in a $\mathrm{S} / \mathrm{C} / \mathrm{B}=100: 1: 5$ was first prepared. This reaction provided $(S)-5$ a with full conversion and with $99 \%$ ee, demonstrating the effectiveness of the sodium base. Subsequent hydrogenations prepared under these reaction conditions, but using toluene or a toluene/ ${ }^{\mathrm{t}} \mathrm{BuOH}(1: 1)$ mixture as solvents, notably showed a complete reaction and the same enantioselectivity. This indicates that a protonation step by an alcohol is not needed to complete the hydrogenation catalytic cycle, nor the requisite hydride is generated in this cycle from a ruthenium isopropoxide. ${ }^{27}$

In addition we have performed diverse experiments with several complexes 1 and different amounts of base (either $\mathrm{KO}^{\mathrm{H}} \mathrm{Bu}$ or $\mathrm{NaO} \mathrm{Pr}$ ) and reaction conditions, trying to observe the purported hydride intermediates. These attempts unfortunately led to complex mixtures which have precluded us to give more conclusive mechanistic information. Notwithstanding that, the lack of $\mathrm{NH}$ groups in compounds 1 and the ability of catalysts from $\mathbf{1 d}$ and $\mathbf{1 j}$ to reduce $\mathrm{C}=\mathrm{C}$ bonds, which does not match with the typical reactivity of a catalyst operating by an outer-sphere mechanism, ${ }^{28}$ seems to suggest an inner sphere mechanism in the present case, involving a hydride imine complex (H, Scheme 5). ${ }^{29}, 30$ Subsequent imine insertion should provide an unsaturated amine complex (I) which either under hydrogenation or transfer hydrogenation conditions should regenerate the starting hydride G. Upon literature information, ${ }^{27}$ the intermediacy of hydrogen complex (J) and alkoxide (K) can tentatively be proposed, respectively, under these reaction conditions.

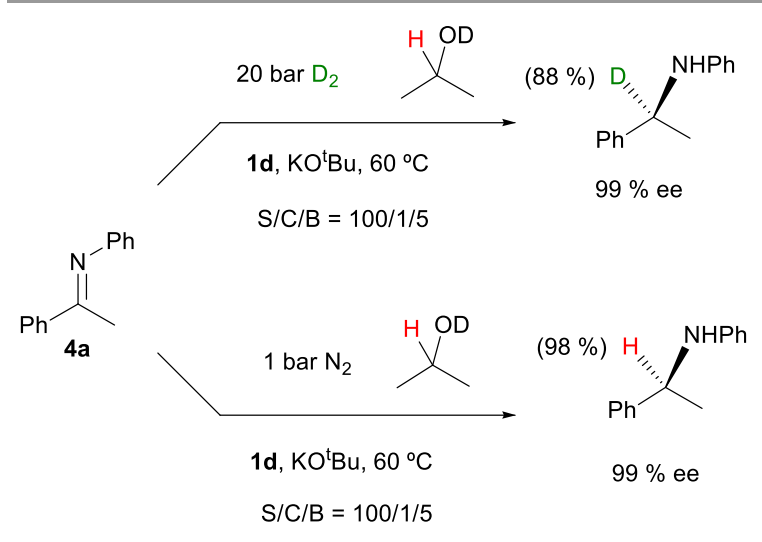

Scheme 4. Deuterium labelling observed in the reduction of $\mathbf{4 a}$ with $\mathbf{1 d}$.

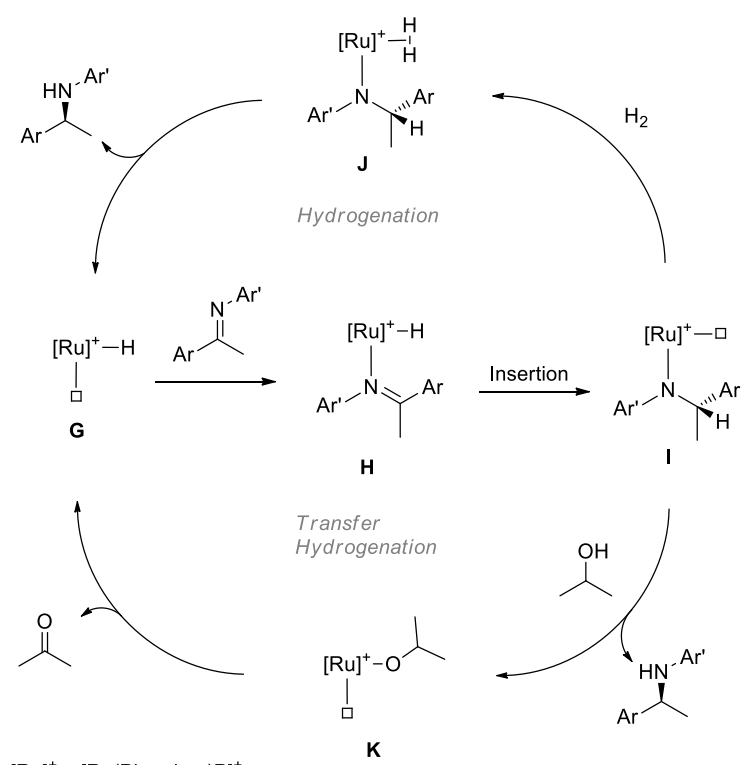

$[\mathrm{Ru}]^{+}=[\mathrm{Ru}(\mathrm{Ph}-\text { pybox }) \mathrm{P}]^{+}$

Scheme 5. Schematic mechanism proposed for the reduction of imines 4 . (a)

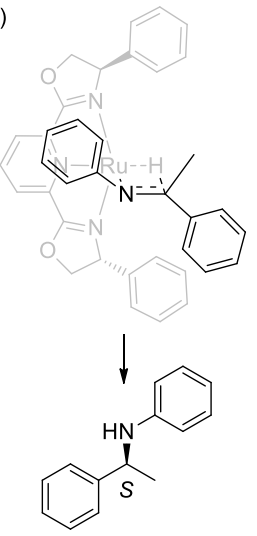

(b)

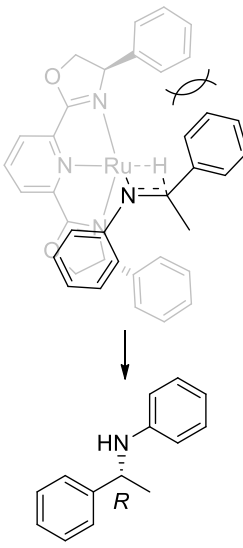

Figure 6. Proposed structures for transition states for the imine insertion step (charge and $\mathrm{P}$ ligand have been omitted for clarity).

On the other hand, the rather similar enantioselectivitites offered by complexes $\mathbf{1} \mathbf{d}$ and $\mathbf{1} \mathbf{j}$ in the reduction of diverse 
imines 4 under hydrogenation and hydrogen transfer conditions, point to a common (or essentially very similar) enantiodetermining step for both types of processes. ${ }^{19 c} \mathrm{~A}$ plausible proposal for this step is the mentioned imine insertion step. ${ }^{27 a}$, 29 Upon this assumption, a reasonable stereochemical model to explain product configuration considers coordination of the hydride and imine trans to the pyridine and the $\mathrm{P}$ ligand, respectively in complex $\mathbf{H}$ (Figure 6). Due to the prochiral nature of the imine, two possible diastereomers for the transition states of the imine insertion step are then possible. These species differ in the interaction between the C-aryl of the imine and the Ph pybox substituents, and upon this interaction, a preferential formation of the $S$ amine should be expected from 1j (Figure 6a). ${ }^{31}$ Following analogous considerations, the formation of the $R$ amine from indane-pybox catalysts can also be explained.

\section{Conclusions}

In the reduction of imines $\mathbf{4}$ under hydrogenation and transfer hydrogenation conditions with $\mathrm{Ru}$ complexes of formula $\left[\mathrm{RuCl}_{2}(\mathrm{R}\right.$-pybox)(L)], a critical influence of the $R$ pybox substituent and the $L$ ancillary ligand has been observed. First, better enantioselectivities were provided by catalysts based on Ph-pybox and indane-pybox over those based on iPr-pybox ligands. Regarding ligand $\mathrm{L}$, catalysts bearing $\pi$-acidic phosphorus ligands provided a significantly better performance both in enantioselectivity and catalyst activity over those bearing $\mathrm{PPh}_{3}$, isonitriles or $\mathrm{MeCN}$ ligands. Overall, the best catalyst along the series possess $\mathrm{Ph}$-pybox and $\mathrm{PPh}(\mathrm{OMe})_{2}$ ligands (1j). This catalyst clearly outperformed our previous best example (found in our preliminary communication) based on a $\mathrm{P}(\mathrm{OMe})_{3}$ ligand (1d). Thus, $\mathbf{1 j}$ was able to provide the highly enantioselective reduction of a wide variety of $\mathrm{N}$-aryl imines 4 derived from aryl alkyl ketones with exceedingly high enantioselectivities, including synthetically relevant substrates $\mathbf{4 I}, \mathbf{4 m}, \mathbf{4 0}$ and $\mathbf{4 p}$. Worth to note, finally, $\mathbf{1 j}$ is the more enantioselective catalyst to date for the transfer hydrogenations of these imines in isopropanol.

\section{Conflicts of interest}

There are no conflicts to declare.

\section{Acknowledgements}

We gratefully thank Ministerio de Economia, Industria y Competitividad of Spain for financial support (Grants CTQ201342501-P, CTQ2016-75193-P and CTQ2016-81797-REDC; AEI/FEDER, UE). E. de J. and E. M. P. thank the FICYT (Principado de Asturias, Spain) for a Ph.D. fellowship.

\section{Notes and references}

1 (a) N. Fleury-Brégeot, V. de la Fuente, S. Castillón and C. Claver, ChemCatChem, 2010, 2, 1346; (b) T. C. Nugent and M.
El-Shazly, Adv. Synth. Catal., 2010, 352, 753; (c) J.-H. Xie, S.-F. Zhu and Q.-L. Zhou, Chem. Rev., 2011, 111, 1713; (d) K. H. Hopmann and A. Bayer, Coord. Chem. Rev., 2014, 268, 59.

2 (a) M. Breuer, K. Ditrich, T. Habicher, B. Hauer, M. Keßeler, R. Stürmer and T. Zelinski, Angew. Chem. Int. Ed., 2004, 43, 788; (b) V. Farina, J. T. Reeves, C. H. Senanayake and J. J. Song, Chem. Rev., 2006, 106, 2734; (c) B. S. Sekhon, J. Mod. Med. Chem., 2013, 1, 10; (d) G. B. Shinde, N. C. Niphade, S. P. Deshmukh, R. B. Toche and V. T. Mathad, Org. Process Res. Dev., 2011, 15, 455; (e) A. Chelouan, R. Recio, L. G. Borrego, E. Álvarez, N. Khiar and I. Fernández, Org. Lett., 2016, 18, 3258; (f) P.-C. Yan, G.-L. Zhu, J.-H. Xie, X.-D. Zhang, Q.-L. Zhou, Y.-Q. Li, W.-H. Shen and D.-Q. Che, Org. Process Res. Dev., 2013, 17, 307; $(g)$ A. Grajewska and M. D. Rozwadowska, Tetrahedron Asymmetry, 2007, 18, 557; (h) H.-U. Blaser, Adv. Synth. Catal., 2002, 344, 17; (i) J. G. Sweeny, L. L. D. Angelo, E. A. Ricks and G. A. Iacobuccit, J. Agric. Food. Chem., 2000, 4, 1969.

3 (a) C. Moessner and C. Bolm, Angew. Chem. Int. Ed., 2005, 44, 7564; (b) N. Mršić, A. J. Minnaard, B. L. Feringa and J. G. de Vries, J. Am. Chem. Soc., 2009, 131, 8358; (c) W. Li, G. Hou, M. Chang and X. Zhang, Adv. Synth. Catal., 2009, 351, 3123; (d) G. Hou, R. Tao, Y. Sun, X. Zhang and F. Gosselin, J. Am. Chem. Soc., 2010, 132, 2124; (e) C.-J. Hou, Y.-H. Wang, Z. Zheng, J. Xu and X.-P. Hu, Org. Lett., 2012, 14, 3554.; (f) Y. Schramm, F. Barrios-Landeros and A. Pfaltz, Chem. Sci., 2013, 4, 2760; $(g)$ W. Tang, S. Johnston, C. Li, J. A. Iggo, J. Bacsa and J. Xiao, Chem. Eur. J., 2013, 19, 14187; (h) C. Guo, D.-W. Sun, S. Yang, S.-J. Mao, X.-H. Xu, S.-F. Zhu and Q.-L. Zhou, J. Am. Chem. Soc., 2015, 137, 90; (i) D. Kong, M. Li, G. Zi, G. Hou and Y. He, J. Org. Chem., 2016, 81, 6640.

4 For some representative examples, see: $(a)$ C. A. Willoughby and S. L. Buchwald, J. Am. Chem. Soc., 1994, 116, 8952; (b) Y.Q. Wang, S.-M. Lu and Y.-G. Zhou, J. Org. Chem., 2007, 72, 3729; (c) S. Zhou, S. Fleischer, K. Junge and M. Beller, Angew. Chem. Int. Ed. 2011, 50, 5120; (d) Q. Zhao, J. Wen, R. Tan, K. Huang, P. Metola, R. Wang, E. V Anslyn and X. Zhang, Angew. Chem Int. Ed., 2014, 53, 8467; (e) For Ru examples see Refs 59.

5 K. Abdur-Rashid, A. J. Lough and R. H. Morris, Organometallics, 2001, 20, 1047.

6 C. J. Cobley and J. P. Henschke, Adv. Synth. Catal., 2003, 345, 195.

7 N. Arai, N. Utsumi, Y. Matsumoto, K. Murata, K. Tsutsumi and T. Ohkuma, Adv. Synth. Catal., 2012, 354, 2089.

8 M. Vaquero, A. Suárez, S. Vargas, G. Bottari, E. Álvarez and A. Pizzano, Chem. Eur. J., 2012, 18, 15586.

9 (a) F. Chen, T. Wang, Y. He, Z. Ding, Z. Li, L. Xu and Q.-H. Fan, Chem. Eur. J., 2011, 17, 1109; (b) F. Chen, Z. Ding, Y. He, J. Qin, T. Wang and Q. H. Fan, Tetrahedron, 2012, 68, 5248.

10 (a) C. Wang, X. Wu and J. Xiao, Chem. Asian J., 2008, 3, 1750; (b) F. Foubelo and M. Yus, Chem. Rec., 2015, 15, 907; (c) D. Wang and D. Astruc, Chem. Rev., 2015, 115, 6621.

11 (a) N. Uematsu, A. Fujii, S. Hashiguchi, T. Ikariya and R. Noyori, J. Am. Chem. Soc., 1996, 118, 4916; (b) C. Wang, A. Pettman, J. Basca and J. Xiao, Angew. Chem. Int. Ed., 2010, 49, 7548; (c) Q. Lei, Y. Wei, D. Talwar, C. Wang, D. Xue and J. Xiao, Chem. Eur. J., 2013, 19, 4021.

12 (a) A. A. Mikhailine, M. I. Maishan and R. H. Morris, Org. Lett., 2012, 14, 4638; (b) W. Zuo, A. J. Lough, Y. F. Li and R. H. Morris, Science, 2013, 342, 1080.

13 S. Zhou, S. Fleischer, K. Junge, S. Das, D. Addis and M. Beller, Angew. Chem. Int. Ed., 2010, 49, 8121.

14 For the diastereoselective transfer hydrogenation of $\mathrm{N}$ sulfinyl imines using 'PrOH, see: (a) D. Guijarro, Ó. Pablo and M. Yus, Tetrahedron Lett., 2009, 50, 5386; (b) Ó. Pablo, D. Guijarro and M. Yus, J. Org. Chem., 2013, 78, 9181.

15 H. J. Pan, Y. Zhang, C. Shan, Z. Yu, Y. Lan and Y. Zhao, Angew. Chem. Int. Ed., 2016, 55, 9615. 
16 J. S. M. Samec and J.-E. Bäckvall, Chem. Eur. J., 2002, 8, 2955.

17 X. Dou and T. Hayashi, Adv. Synth. Catal., 2016, 358, 1054.

18 E. Menéndez-Pedregal, M. Vaquero, E. Lastra, P. Gamasa and A. Pizzano, Chem. Eur. J., 2015, 21, 549.

19 (a) V. Rautenstrauch, X. Hoang-Cong, R. Churlaud, K. AbdurRashid and R. H. Morris, Chem. Eur. J., 2003, 9, 4954; (b) C. A. Sandoval, T. Ohkuma, N. Utsumi, K. Tsutsumi, K. Murata and R. Noyori, Chem. Asian J., 2006, 1, 102; (c) W. Baratta, M. Ballico, G. Chelucci, K. Siega and P. Rigo, Angew. Chem. Int. Ed., 2008, 47, 4362; (d) C. A. Sandoval, Y. Li, K. Ding and R. Noyori, Chem. Asian J., 2008, 3, 1801; (e) T. Touge, T. Hakamata, H. Nara, T. Kobayashi, N. Sayo, T. Saito, Y. Kayaki and T. Ikariya, J. Am. Chem. Soc., 2011, 133, 14960.

20 (a) E. Menéndez-Pedregal, J. Díez, Á. Manteca, J. Sánchez, A. C. Bento, R. García-Navas, F. Mollinedo, M. P. Gamasa and E. Lastra, Dalton Trans., 2013, 42, 13955; (b) D. Cuervo, E. Menéndez-Pedregal, J. Díez and M. P. Gamasa, J. Organomet. Chem., 2011, 696, 1861.

21 The synthesis and characterization of a series of $\mathrm{NHC}$ derivatives of formula $\left[\mathrm{RuCl}_{2}(\mathrm{R}\right.$-pybox $\left.)(\mathrm{NHC})\right]$ is under progress and it will be reported in due course.

22 (a) Y. Chi, Y. Zhou and X. Zhang, J. Org. Chem. 2003, 4120; (b) S. L. De Marin, T. Martens, C. Mioskowski and J. Royer, J. Org. Chem., 2005, 70, 10592; (c) J. M. M. Verkade, L. J. C. van Hemert, P. J. L. M. Quaedflieg, P. L. Alsters, F. L. van Delft and F. P. J. T. Rutjes, Tetrahedron Lett., 2006, 47, 8109.

23 S. Y. Shirai, H. Nara, Y. Kayaki and T. Ikariya, Organometallics, 2009, 28, 802.

24 M. Krompiec, S.; Mazik, M.; Zielinski, W.; Smolik, Pol. J. Chem., 1996, 70, 1223.

25 C. K. Govindan and G. Taylor, J. Org. Chem., 1983, 48, 5348.

26 D. Cuervo, M. P. Gamasa and J. Gimeno, Chem. Eur. J., 2004, 10, 425.

27 (a) S. E. Clapham, A. Hadzovic and R. H. Morris, Coord. Chem Rev., 2004, 248, 2201; (b) J. S. M. Samec, J.-E. Bäckvall, P. G. Andersson and P. Brandt, Chem. Soc. Rev., 2006, 35, 237.

28 Ikariya and coworkers described that the hydrogenation of $4 \mathbf{u}$ by an Ir catalyst operating by an outer-sphere mechanism, cleanly hydrogenated the $\mathrm{C}=\mathrm{N}$ bond (Ref. 23). On the other hand, Morris and coworkers have observed a significant amount of the allyl product in the hydrogenation of the $N$ phenyl analog of $\mathbf{4 t}$ with a $\mathrm{Ru}$ diphosphine diamine type catalyst (Ref 5).

29 Plietker et al have observed that a cationic complex of formula $[\mathrm{Ru}(\mathrm{Cl})(\mathrm{PNNP})(\mathrm{NCMe})] \mathrm{PF}_{6}$ based on a tetradentated diphosphine diamine ligand devoided of $\mathrm{NH}$ fragments (PNNP) is highly active in the reduction of ketones and aldimines using either hydrogen or $\mathrm{PrOH}$, proposing the participation of a key cationic unsaturated hydride $[\mathrm{Ru}(\mathrm{H})(\mathrm{PNNP})]^{+}$for both processes: S.-F. Hsu and B. Plietker, Chem. Eur. J., 2014, 20, 4242.

30 For a similar inner sphere mechanism for imine reduction, see: E. Mizushima, M. Yamaguchi and T. Yamagishi, J. Mol. Catal. A Chem., 1999, 148, 69.

31 A similar model has been proposed in the transfer hydrogenation of acetophenone with complex $\mathbf{1 b}$ (Ref 26$)$. 